\title{
Teachers' Turnover in Private Secondary Schools of Karachi (Pakistan)
}

\author{
Muhabat Khan ${ }^{1}$, Professor Dr. Syed Abdul Aziz ${ }^{2}$ \\ 1(Research Scholar HIESS, Hamdard University Karachi, Pakistan) \\ 2(Research Supervisor \& Dean, HIESS, Hamdard University Karachi, Pakistan)
}

\begin{abstract}
The main concern of the researcher was to focus on teachers' turnover in private secondary schools of Karachi. Two hypotheses related to the demographic variables, such as sex, and qualification were devised for the study. The population of the study was large and diverse, hence stratified random sampling design was used to select the respondents who were the teachers and principals. The sample size was 160 teachers and 10 principals from 40 private secondary schools of Karachi. Questionnaire and interview were the research instruments. The collected data was analyzed through percentage and ' $t$ ' test. Job insecurity and low salary were found the major factors influencing on the turnover of teachers in private secondary schools of Karachi.
\end{abstract}

Key words: Teachers' turnover, private, secondary school

\section{Introduction}

Teachers' turnover is a sever problem in private secondary schools of Karachi. It is a challenging problem for the school administrators to retain qualified and experienced teachers in their institutions. Advertisement for secondary school teachers on regular basis in various newspapers is an evident for the mentioned problem. For example, on the Dawn, $5^{\text {th }}$ May, (2013) an advertisement related to "a well known English Medium secondary school urgently requires teachers for different subjects." In these schools, recruitment process is never ending throughout the session.

Ingersoll, (2004) concluded that a proper attention should be paid on the retention of teachers rather than recruiting new teachers. He recommended good salary, valuing their opinions in the decision making process and helping them in students' disciplinary issues in the context of decreasing the rate of teachers' turnover, as it also influences on the output of students. Sutherland \& Jordaan, (2004) stated that turnover of employees happens due to financial related issues. They keep changing their schools and sometimes teaching profession for better opportunity elsewhere.

The overall purpose of the study was to critically analyze the teachers' turnover in private secondary schools of Karachi, and make suggestions for eradicating the turnover of teachers and restore their value. In more precise terms, the study tested the following null hypotheses:

There will be no significant difference in the rate of turnover among trained and untrained teachers due to job insecurity in private schools. There will be no significant difference in the rate of turnover among the male and female teachers due to salary package in private schools.

This study is expected to yield, benefits for the following stake holders:

It will help in advancement of knowledge related to the concept of turnover.

It will help the authorities concerned to take appropriate measures to check the turnover.

The study was limited to teachers, principals and experts of secondary schools in Karachi.

\section{Liiterature Review}

Macy \& Mirvis (1976) stated that turnover means "any departure beyond organizational boundaries". Turnover has been measured the most serious and extensive problem that many educational organizations all around the world suffer from.

Ingersoll, (2001) elaborated the teachers' turnover with an organizational perspective, considering teachers' movement from individual school. He has established that the characteristics of individual teacher lead to differing turnover states, teachers inclined to leave schools where there are administrative effectiveness problems, deficiency of resources and lack of satisfaction. These individuals perhaps leaving teaching forever or they may be moving to another school where their needs are fulfilled. In both the cases, turnover is a serious failure for the school organization. Ronfeldt and his colleagues (2011) have derived that teachers' turnover not only lessens the achievement level of students, but it also disorders the entire organization of the school. Ingersoll and Smith (2003) have revealed the facts that teachers' turnover is equally divided into two categories: 1) attrition; and 2) migration. Attrition means to change the profession and migration means moving to other schools in the same profession. Gary, B. et al (2007 stated that high level of turnover has three major 
drawbacks: 1) to replace the teacher is not an easy task; 2) recruitment does cost; 3) to train the new teacher is crucial.

Ingersoll, (2004) stated that more attention should be paid to resolve teacher' turnover rather than to encourage increased recruitment. He suggested that turnover should be dealt in terms of increasing teachers' salary, valuing their opinions in decision making programme and eliminating student discipline problems. In this regard, the private schools can modify their strategies, to revise the experienced staff salary scale, encourage their efforts and help them against the misbehaved students in the classroom to minimize teachers' turnover. Candle, J. (2010) declared that it is the nature of all human beings to seek employment where their needs are satisfied because they do not have loyalty to any organization unless their needs are fulfilled and lead a contented life.

Onen, D. (2005) divided the teachers' dropout factors into three categories; namely, employer related factors, consisting on salary, supervision and poor working condition; secondly, employee related factors, containing on job satisfaction, personal decision and career growth; finally, external factors, including on better pay elsewhere, competitive condition and low status, which influence on the dropout of teachers in private secondary schools.

\section{Methodology}

The strategy of research was mixed research approach. The population of the study comprised of all the private secondary school teachers of Karachi. The sampling frame of the study was obtained from the office of education directorate. Stratified random sampling was adopted. Overall sample size was 160 teachers and 10 principals from 40 private secondary schools of Karachi. The study used a self-administered questionnaire and an interview protocol to collect data from teachers and principals. The data were analyzed statistically.

\section{Composition Of The Sample}

Table 4.1

Distribution of Private Secondary School Teachers of Karachi by Professional Qualification.

\begin{tabular}{|l|l|l|}
\hline $\begin{array}{l}\text { Professional } \\
\text { Qualification }\end{array}$ & Frequency & Percentage \\
\hline Trained & $\mathbf{8 3}$ & $\mathbf{5 2}$ \\
\hline Untrained & $\mathbf{7 7}$ & $\mathbf{4 8}$ \\
\hline Total & $\mathbf{1 6 0}$ & $\mathbf{1 0 0}$ \\
\hline
\end{tabular}

It is evident from the table that out of 160 teachers, $90 \%$ were trained and $48 \%$ were untrained.

Table 4.2

Distribution of Private Secondary School Teachers of Karachi by Sex.

\begin{tabular}{|l|l|l|}
\hline Sex & Frequency & Percentage \\
\hline Male & 48 & $\mathbf{3 0}$ \\
\hline Female & 112 & $\mathbf{7 0}$ \\
\hline Total & 160 & 100 \\
\hline
\end{tabular}

It is evident from the table that out of 160 teachers, $70 \%$ were female and $30 \%$ male. Table 4.1 .2 depicts the distribution of Private Secondary School Teachers of Karachi by sex.

There will be no significant difference in the rate of turnover among trained and untrained teachers due to job insecurity in private secondary schools.

\section{Analysis of the Problem}

(1) $H_{O}: \mu_{1}=\mu_{2}$, (2) $H_{1}: \mu_{1} \neq \mu_{2}$, (3) $\alpha=0.05$, (4) Test Statistic: $\mathbf{t}=2.50$,

(5) Decision rule: Reject $H_{O}$ if computed $\mathrm{t} \geq 1.96$.

Conclusion: Referring to table $t$, we found that the tabulated value of $t=1.96$ with $\mathrm{df}=158$ at $\alpha=0.05$ is less than the computed value of $t=2.50$. Thus, the null hypothesis is rejected and it is concluded that there is significant difference in the rate of turnover between trained and untrained teachers in private secondary schools. From inspection of the table, it is clear that trained teachers are more affected by job insecurity in private secondary schools.

There will be no significant difference in the rate of turnover among the male and female teachers due to salary package in private schools.
(1) $H_{O}: \mu_{1}=\mu_{2}$
(2) $H_{1}: \mu_{1} \neq \mu_{2}$,
(3) $\alpha=0.05$,
(4) Test Statistic: $t=2.51,(5)$ Decision rule: Reject $H_{O}$ if computed $\mathrm{t} \geq 1.96$

Conclusion: Referring to table $t$, we found that the tabulated value of $t=1.96$ with $\mathrm{df}=158$ at $\alpha=$ 0.05 is less than the computed value of $t=2.51$. Thus, the null hypothesis is rejected and it is concluded that there is significant difference in the rate of turnover between the male and female teachers in private secondary 
schools. From inspection of the table, it is clear that female teachers are more affected by low salary package of private secondary schools.

\section{Conclusion:}

The study was planned through the review of the related literature, questionnaire and interview to find the major factors influencing on teachers' turnover in private secondary schools of Karachi. The study found that trained teachers were more likely to turnover from schools as compare to untrained teachers due to job insecurity. Similarly, the turnover rate of female teachers was comparatively higher than male teachers due to poor salary package. Both the factors were found strongly affecting on the turnover of teachers in private secondary schools of Karachi.

\section{Recommendations:}

It is recommended that all the stake holders particularly the principals, administrators, managers and head-teachers must design certain policies for teachers' job security to reduce the turnover ratio in their schools. It is strongly recommended to increase their salary packages to gratify their needs and lead a happy life in the society. Moreover, they will stay for a longer period in private secondary schools of karachi.

\section{References}

[1] Gary Barnes, Edward Crowe and Benjamin Schaefer, (2007). "The Cost of Teacher Turnover in Five School Districts: A Pilot Study" (Washington: National Commission on Teaching and America's Future.

[2] Ingersoll, R. (2001). "Teacher Turnover and Teacher Shortages: An Organizational Analysis."American Education Research Journal, 38, 499-534.

[3] Ingersoll, R. M., \& Smith, T. M. (2003). The wrong solution to the teacher shortage. Educational Leadership, 60(8), 30-33.

[4] Ingersoll, R. (2004). Revolving Doors and LeakyBuckets. In C. Glickman (Ed.) Lettersto the Next Presidents: What We Can Do About the Real Crisis in Public Education (pp. 141-147). New York: Teachers College Press.

[5] Juliet Candle, (2010). Factors Affecting Teacher Turnover in Private Secondary Schools in Wakiso district. REG. 2004/HDO4/0688U

[6] Macy, B. A., and Mirvis, P. H. (1976). A methodology for assessment of quality of work and organizational effectiveness in behavioral economic terms, pp321-332.

[7] Onen, D. (2005). A general guide to writing research proposal and report. Options press and publishers.

[8] Ronfeldt, M., Lankford, H., \& Wyckoff, J. (2011). How teacher turnover harms student achievement. NBER Working Paper No.17176.

[9] Sutherland,M. \& Jordaan,W. (2004) Factors Affecting the Relation of Knowledge Workers. South African Journal of Human Resource Management, 2(2),63-72. 